\title{
O papel da mulher na sociedade portuguesa: um olhar pelo lado de fora (uma breve revisão)
}

\begin{abstract}
Resumo:
Se olharmos para a história de Portugal, veremos que antigamente as mulheres eram tidas como empregadas domésticas, não tinham direito à educação, liberdade de expressão, eram subjugadas às vontades dos homens. A proclamação da República em 1910 acalentou nas mulheres a esperança de alterações na sua posição social. Contudo foi só depois da Revolução dos Cravos que as mulheres portuguesas passaram ao estatuto de igualdade com o homem na família e a participação delas nas áreas da ciência, cultura, comunicação social e do desporto passou a crescer. A mulher portuguesa atual casa e procria mais tarde, tem ensino superior, ocupa cargos importantes, mas ainda é mais vulnerável socialmente. Tal situação pode ser comparada com a na sociedade russa, mas só em parte.
\end{abstract}

Palavras-chave: mulheres, feminismo, sociedade, liberdade, direitos

\begin{abstract}
:
The Role of Women in Portuguese Society: An Outside View (a Short Review) If we look at the history of Portugal, we will see that in the past women were mostly seen as domestic servants, had no access to education, were deprived of their freedom of expression, and were subjugated to the will of men. The proclamation of the Republic in 1910 gave the women of Portugal hope for a change in their social position. However, it was the Carnation Revolution of 1974 that resulted in Portuguese women getting equal rights with men within the family. Moreover, after the Carnation Revolution the role of women in science, culture,
\end{abstract}


social communication and sport began to grow. Today, an average Portuguese woman tends to marry and procreate later, have a higher level of education, occupy positions of certain importance, but she still remains more socially vulnerable. Such a situation can be compared with that in Russian society, but only in part.

Keywords: women, feminism, society, freedom, rights

\section{Introdução}

Hoje em dia o papel da mulher na sociedade portuguesa é um tema discutido em diversos simpósios, conferências, colóquios, analisado em livros e artigos etc. No entanto, a maioria dos estudos é dedicada ora à história da luta das mulheres pelos seus direitos, ora ao contributo delas em diferentes áreas. Quase não há pesquisas abrangentes pelo que tomei a decisão de analisar o caminho percorrido pelas mulheres portuguesas no processo da sua emancipação e o seu papel na sociedade contemporânea em conjunto. Além disso, nunca foi efetuada uma comparação da situação das mulheres em Portugal e na Rússia, sendo por isso o outro objetivo do presente artigo comparar certos aspetos da questão feminina nos dois países. Todavia, como o tamanho do artigo é limitado, vou realizar apenas uma curta revisão do problema.

A relevância do artigo pode ser comprovada pela necessidade de ressaltar a importância das mulheres portuguesas para o processo histórico nas condições em que continuam a ser oprimidas tanto no seio familiar como no trabalho, tendo em conta os casos de violência mais recentes.

\section{Período da monarquia}

Durante muitos séculos Portugal foi um dos países que atribuiu à mulher funções secundárias, menosprezando os seus talentos e capacidades. A mulher era quase totalmente subordinada ao homem, não tinha direitos legais.

Com efeito, a situação dependia da classe social dela. Se fosse de uma família pobre, exercia papéis exclusivamente tradicionais de mãe 
e esposa. Se pertencesse a uma família nobre, podia ser dama ou cortesã, intelectual, artista. São principalmente representantes da classe alta que entraram na história no período da monarquia, por exemplo: D. Teresa de Aragão; D. Urraca de Castela; D. Filipa de Lencastre; D. Beatriz, Infanta de Portugal (Liñares [et al.], vol. 1, 2014: 9-10). Se não quisesse casar, podia entrar num convento em que obtinha a oportunidade de desenvolver as suas capacidades intelectuais. Assim foram três freiras - Sóror Violante do Céu, Sóror Maria do Céu e Sóror Madalena da Glória - que se tornaram as principais escritoras portuguesas da época barroco (Hatherly, 1996: 274, 277).

No entanto, nos séculos XVI-XVII a situação das mulheres passou a atrair a atenção dos homens ilustres da época. Em 1557 Ruy Gonçalves publicou o primeiro livro feminista português "Dos privilégios e prerrogativas que o gênero feminino tem por direito comum e Ordenações do Reino, mais que o gênero masculino". Em 1603 as Ordenações Filipinas concederam às mulheres solteiras ou viúvas o direito de vender, comprar ou arrendar.

Em 1790, por ordem da Rainha D. Maria I, a primeira mulher a ocupar o trono de Portugal, foram criadas as primeiras escolas para meninas. Em 1807 o primeiro periódico feminino "O Correio das Modas", e em 1868 - o primeiro jornal radicalmente feminista "A Voz Feminina" - foram publicados. Em 1870 as portas da faculdade de medicina foram abertas às mulheres e no mesmo ano uma nova classe de empregados telegráficos que podiam ser do sexo feminino foi criada.

Já no limiar dos séculos XIX-XX a luta pela autoafirmação feminina resultou na fundação da Federação Socialista do Sexo Feminino em 1897, da Liga Portuguesa da Paz em 1899, da Liga Republicana das Mulheres Portuguesas em 1908 (Liñares [et al.], vol. 1, 2014: 12-73).

A despeito disso, os resultados reais obtidos no período de monarquia eram escassos. Em 1909 as raparigas representavam apenas 9,5\% de todos os alunos dos liceus. As mulheres não tinham direito de voto nem o direito a trabalhar na função pública. De acordo com o Código Penal de 1886, a mulher casada era punida com prisão maior celular de 2 a 8 anos no caso do adultério (o homem era apenas condenado a uma multa) (ibidem: 60, 76; Pimentel (1), 2010). 
Neste contexto torna-se compreensível que as mulheres feministas do início do século XX se empenhassem de forma enérgica no derrube da monarquia. Esperavam que com ele uma legislação favorável às mulheres fosse promulgada.

Entretanto, se compararmos o período monárquico em Portugal com o mesmo período na Rússia, verificaremos que a sociedade russa também era patriarcal e segundo o livro "Domosstrói" publicado no século XVI, a posição da era nula. As primeiras reformas foram introduzidas só no século XVIII, no reinado de Pedro I. Já no século XIX apareceram os primeiros estudos ligados ao problema da emancipação das mulheres.

\section{A Primeira República e início da Ditadura Militar}

Não é de negar que com a proclamação da República a 5 de Outubro de 1910 a situação das mulheres tenha melhorado significativamente.

Segundo a Lei do Divórcio de 1910, marido e mulher terão tratamento equivalente em relação aos motivos do divórcio e direitos sobre os filhos e serão punidos da mesma forma pelo adultério. A escola tornou-se obrigatória para crianças dos dois sexos dos 7 aos 11 anos. As mulheres passaram a ter o direito a trabalhar na função pública e em 1930 constituíam 7,1\% de todo o funcionalismo do Estado (Liñares [et al.], vol. 1, 2014: 75-109).

O movimento feminista ampliou-se. De 1911 a 1916 foram fundados organismos tais como a Associação de Propaganda Feminista, a Comissão Feminina «Pela Pátria», o Conselho Nacional das Mulheres Portuguesas, a Cruzada das Mulheres Portuguesas (Brito Jorge, 2010). Em 1924 realizou-se o $1^{\circ}$ e em 1928 o $2^{\circ}$ Congressos Feministas.

Porém, o alvo principal das mulheres não veio a ser atingido. O sufrágio feminino não foi conseguido, apesar de em 28 de Maio de 1911 Carolina Beatriz Angelo votar nas eleições para a Assembleia Constituinte em Lisboa. ${ }^{1}$ Quer isto dizer que nem mesmo com a implantação da República se mudaram os preconceitos em relação à mulher.

\footnotetext{
${ }^{1}$ Para saber mais consulte (Vicente [1], 2010).
} 
Ao contrário daquilo que acontecia em Portugal, na Rússia após a Revolução de 1917 foi anunciada a igualdade entre homens e mulheres.

\section{O Estado Novo}

Com o advento do Estado Novo em 1933 as mulheres perderam completamente os seus direitos. Elas não podiam votar, ser diplomatas, juízes ou trabalhar na administração local. Auferiam salários menores que os homens pelo mesmo trabalho. As professoras primárias tinham de pedir autorização do governo para se casarem, as telefonistas, as enfermeiras, as hospedeiras de ar estavam mesmo proibidas de contrair matrimónio (Pereira, 2015). Mais do que isso, as mulheres casadas não podiam trabalhar no comércio, viajar para fora do país, administrar bens ou abrir contas bancárias sem o consentimento do marido. $\mathrm{O}$ divórcio para os que se casassem na igreja era proibido. $\mathrm{O}$ aborto era punido com pena de prisão.

O movimento feminino da altura também era controlado pelo regime. Em 1936 o governo impulsionou a criação de organismos como a Obra das Mães pela Educação Nacional e a Mocidade Portuguesa Feminina, e em 1961 - do Movimento Nacional Feminino. Contudo, esses órgãos pouco tinham a ver com o processo de emancipação de mulheres, o objetivo deles era a formação ideológica feminina.

No entanto, o período do Estado Novo trouxe muitas figuras eminentes, como: Maria Lamas, jornalista que publicou o livro "As mulheres do meu País" (1948); Dália Cunha, Natália Cunha e Maria Laura Amorim, as primeiras mulheres portuguesas a participar nos Jogos Olímpicos (1952); Isabel Magalhães Colaço, a primeira mulher a doutorar-se em Direito (1954) (Liñares [et al.], vol 1, 2014: 122; 124; vol. 2, 2014: 10); Amália Rodrigues, Rainha do fado português.

Além disso, percebendo a importância das mulheres na luta pela moralização e educação da sociedade, em 1931 o Estado Novo tornou-se o primeiro regime português a conceder às mulheres o direito de voto, embora com certas limitações. Em 1935 foram eleitas as primeiras mulheres deputadas à Assembleia Nacional: Domitila de Carvalho, 
Maria Cândida Bragança Parreira e Maria Guardiola. Finalmente a 26 de dezembro de 1968 foi publicada uma lei que acabou por remover qualquer discriminação em função do sexo.

No que toca à sociedade russa no mesmo período de tempo, cabe dizer que ela foi mais progressista. Em 1920 a Rússia Soviética tornou-se o primeiro estado no mundo a autorizar o aborto. Em 1967 as mulheres passaram a receber a pensão alimentícia após o divórcio. Em 1968 a licença de maternidade foi introduzida. As mulheres soviéticas trabalhavam em pé de igualdade com os homens e durante a Segunda Guerra Mundial ocupavam cargos importantes nas empresas e fábricas.

\section{O período "marcelista" e os anos após 25 de Abril}

Na década de 1960, a emigração masculina para a Europa e a guerra colonial tiveram como resultado uma acelerada entrada de mulheres no mundo do trabalho. Elas foram autorizadas a ocupar cargos da administração local, da carreira diplomática e da magistratura judicial. Em 1979 e 1980, a lei declarou igualdade de oportunidades e tratamento a homens e mulheres no trabalho.

$\mathrm{O}$ estatuto de igualdade foi introduzido no direito de família. Em 1969 a mulher casada passou a poder atravessar as fronteiras sem licença do marido. Em 1975-1976 foi alterado o artigo da Concordata que impedia os casados pela Igreja católica de se divorciarem. Foram introduzidas a licença de maternidade de 90 dias e inovações no que dizia respeito aos crimes de violação (Pimentel (2), 2010).

Segundo a Constituição da República Portuguesa de 1976 e a Lei de Recenseamento Eleitoral de 1978, “o sufrágio era universal, igual e secreto..., e o seu exercício... constituía um dever cívico" (Constituição da República Portuguesa).

Quanto às mulheres eminentes do período "marcelista", antes de mais é de mencionar o nome da Eng. ${ }^{a}$ Maria de Lourdes Pintasilgo que se tornou a primeira mulher a desempenhar o cargo de ministra dos Assuntos Sociais em 1974-1975 e o cargo de primeira-ministra de Portugal em 1979-1980; a candidatar-se à Presidência da República 
em 1986; a exercer funções da embaixadora na Unesco, deputada no Parlamento Europeu etc. ${ }^{2}$.

Entretanto, a queda do regime e a instauração da democracia trouxeram muitas outras pioneiras em várias esferas da atividade humana: Madalena Barbosa, fundou o Movimento de Libertação das Mulheres (1974); Ruth Garcês, a primeira mulher a ingressar na carreira de magistratura (1977), fundou a Associação Portuguesa de Mulheres Juízes (1988) (Liñares [et al.], vol. 2, 2014: 26; 33); Rosa Mota, considerada a melhor maratonista de todos os tempos; Maria Barroso Soares, atriz, deputada, primeira-dama de Portugal de 1986 a 1996, esposa do presidente Mário Soares.

Tal como em Portugal, na União Sovética em 1970-1980 iniciou-se um novo movimento civil feminino e passaram a formar-se diversas organizações feministas.

\section{A emancipação da Mulher na Idade Contemporânea}

Hoje em dia Portugal é um país onde a igualdade entre homens e mulheres deixou de ser uma mera utopia. A mulher conquistou o direito ao trabalho, à sua segurança; o acesso à saúde, ao ensino, à participação política. A família, a maternidade, a invalidez, a reforma, a velhice são áreas protegidas pelo Estado.

A 11 de fevereiro de 2007 realizou-se o $2^{\circ}$ referendo sobre a despenalização do aborto (o $1^{\circ}$ tinha-se realizado em 1998), que resultou na legalização do aborto (Referendo - 11/02/2007).

A intervenção das mulheres na vida social, política e económica nas últimas décadas tem-se ampliado cada vez mais. Para entendê-lo basta lembrar os nomes de: Mónica Bettencourt-Dias que por duas vezes venceu o prémio Pfizer em Investigação Básica; Maria de Assunção Esteves, a $1^{\mathrm{a}}$ mulher eleita presidente da Assembleia da Republica Portuguesa (2011-2015); Joana Marques Vidal, a primeira mulher Procuradora-Geral da República; Anabela Rodrigues, a primeira mulher

${ }^{2}$ Para saber mais, consulte os documentos e publicações da autoria de Maria de Lourdes Pintassilgo (Inscrição das Mulheres no Espaço Público: Identidade [s] em Construção). 
a liderar o Ministério da Administração Interna (Liñares [et al.], vol. 2, 2014: 67, 119, 123, 135; Igualdade de género e não discriminação).

No entanto, a sociedade portuguesa contemporânea ainda está longe de corresponder a um ideal, as desigualdades persistem e são notórias. Assim, as mulheres continuam a ser marginalizadas nos cargos de direção. A remuneração média de uma mulher com ensino superior é apenas entre $70,7 \%$ e $71,8 \%$ da remuneração de um homem licenciado, enquanto uma trabalhadora com apenas o $1^{\circ}$ ciclo do Ensino Básico recebe entre $80 \%$ e $83 \%$ da remuneração de um homem. O desemprego das mulheres é tanto mais elevado quanto maior for o nível de escolaridade, e o desemprego total é muito maior nas mulheres do que nos homens (Rosa, 2017). Apesar de o Código Penal ter introduzido alterações, a violência sobre as mulheres continua a ser um dos aspetos mais preocupantes.

$\mathrm{Na}$ Rússia moderna a situação é parecida em alguns aspetos. Por exemplo, as diferenças salariais entre mulheres e homens são tanto maiores quanto mais elevado for o nível de formação. Todavia o desemprego entre as mulheres é inferior àquele entre os homens $(5,3 \%$ contra 5,8\% em 2015). Ao contrário de Portugal, as mulheres estão melhor representadas na administração do estado, segurança social e defesa militar: $6,2 \%$ contra $8,5 \%$ entre os homens em 2015 . Segundo a Constituição os homens e as mulheres têm direitos jurídicos e políticos iguais, contudo as mulheres são protegidas pela Proteção do trabalho feminino que divulga as limitações e os privilégios para as mulheres grávidas, determina as profissões proibidas para as mulheres que possam prejudicar a sua saúde e a sua função genital.

Com efeito, tanto em Portugal, como na Rússia, existem comissões e entidades que se dedicam à defesa e promoção dos direitos das mulheres. Nomeadamente em Portugal, são a Comissão para a Igualdade e para os Direitos das Mulheres, a associação feminista portuguesa Capazes, a Plataforma Portuguesa para os Direitos das Mulheres, a Associação Presença Feminina, o Movimento Democrático de Mulheres, a União de Mulheres Alternativa e Resposta.

Contudo, até hoje em dia são frequentes em Portugal casos de violação, e o comportamento dos juízes que os justificam faz pensar no 
quão perto ainda estamos de um mundo tradicional e obscuro. Neste contexto é de observar que não será possível conseguir a igualdade de oportunidades entre os homens e as mulheres, eliminar a disparidade de género, enquanto a mentalidade da sociedade portuguesa não mudar.

\section{Observação final}

O estudo realizado demostra que o processo de emancipação das mulheres em Portugal foi longo e complicado. Levou muitos séculos para que elas próprias se consciencializassem do seu papel discriminatório na sociedade e do facto de que não só pelos homens deve ser movido o fio condutor da história, para que se alcançasse um tratamento igualitário na família e no trabalho, as mesmas oportunidades de crescimento, valorização e desenvolvimento para homens e mulheres.

Não obstante, as desigualdades que persistem na sociedade portuguesa contemporânea e que parecem estranhas até mesmo em comparação com um país tão conservador como a Rússia, evidenciam que há ainda muito para fazer.

A meu ver, não basta fundar organizações e movimentos feministas para corrigir o estado das coisas. É preciso conduzir uma política de estado razoável: adotar leis destinadas a proteger o trabalho feminino, mudar a atitude dos juízes ou se calhar até ir mais longe e, seguindo o exemplo da Áustria, implementar reformas segundo as quais o trabalho doméstico seria igualado ao trabalho nas empresas e fábricas. Porque na verdade é muito duvidoso que as mulheres portuguesas queiram mesmo alcançar a igualdade plena de direitos com os homens. Não acredito que elas aspirem a sacrificar a maternidade, a família, a vida pessoal pelo trabalho, carreira, papéis de liderança. Ou estarei enganada? 


\section{Referências bibliográficas}

BRITO JORGE, A., "Mulheres da $1^{\text {a }}$ República: a (nossa) dívida", [on-line] https: $/ /$ www.apagina.pt $/ \mathrm{aba}=7 \& \mathrm{cat}=540 \& \mathrm{doc}=14923 \& \mathrm{mid}=2-$ inverno 2010.

Constituição da República Portuguesa - VII rev. 2005, [on-line] https://xn--constituio-n5a1c.pt/.

Federal'na služba gosudarstvennoj statistiki, [on-line] http://www.gks.ru/. GAMEL'KO, E. V. (2010), „Sovetskoe zakonodatel'stvo o položenii ženŝiny v 1917-1930-gg.", Molodoj učenyj, 5(2), Izdatel'stvo Molodoj učenyj, g. Čita, pp. 97-99.

Hatherley, A. (1996), "Tomar a palavra. Aspectos de vida da mulher na sociedade barroca", Revista da Faculdade de Ciências Sociais e Humanas, 9, Edições Colibri, Lisboa, pp. 269-280.

Igualdade de gênero e não discriminação, [on-line] http://www.igualdade. cm-abrantes.pt/docs/dia\%20da\%20mulher.pdf.

Inscrição das Mulheres no Espaço Público: Identidade (s) em Construção, Centro de Documentação e de Publicações da Fundação "Cuidar o Futuro", [on-line] http://www.arquivopintasilgo.pt/MLP/Dossiers/Dossier1/5/ Default.aspx?IdSubDossier $=5$.

LIÑARES, E. (2014), A mulher em Portugal: Alguns aspetos do evoluir da situação feminina na legislação nacional e comunitária, vol. 2, Direção Geral da Segurança Social, Núcleo de Documentação e Divulgação, Lisboa.

LIÑARES, E. (org.) (2014), A mulher em Portugal: Alguns aspetos do evoluir da situação feminina na legislação nacional e comunitária, vol. 1, Direção Geral da Segurança Social, Núcleo de Documentação e Divulgação, Lisboa.

PEREIRA, A., "O Papel da Mulher na Sociedade Portuguesa o Ontem e o Hoje", [on-line] https://prezi.com/2ueal0su-jel/o-papel-da-mulher-na-sociedade-portuguesa-o-ontem-e-o-hoje/ - 3.03.2015.

PIMENTEL, I., “A situação das mulheres no século XX português (Parte I)", [on-line] https://jugular.blogs.sapo.pt/1472030.html - 10.01.2010.

PIMENTEL, I., "A situação das mulheres no século XX português (Parte II)", [on-line] https://jugular.blogs.sapo.pt/1482011.html - 12.01.2010. 
Pordata, base de dados Portugal Contemporâneo, Fundação Francisco Manuel dos Santos, [on-line] https://www.pordata.pt/Portugal.

Referendo - 11/02/2007, Informação Detalhada - Resultados Nacionais, [on-line] http://eleicoes.cne.pt/raster/detalhe.cfm?eleicao=re1\&dia=11\&me $\mathrm{s}=02$ \&ano $=2007 \&$ codreg $=0$ \&local $=0$.

ROSA, E., "A situação atual da mulher em Portugal: alguns dados para reflexão", [on-line] https://www.eugeniorosa.com/Sites/eugeniorosa.com/ Documentos/2017/7-2017-Situacao-mulher-Portugal.pdf - 05.03.2017. VICENTE, A., "Algumas notas sobre as Mulheres e a Primeira República Portuguesa (1)", [on-line] https://caminhosdamemoria.wordpress. com/2010/04/29/algumas-notas-sobre-as-mulheres-e-a-primeira-repu blica-portuguesa-1/-29.04.2010. 